\title{
Clinical and Electrophysiological Study in French-Canadian Population with Charcot-Marie-Tooth Disease Type 1A Associated with 17p11.2 Duplication
}

\author{
Nicolas Dupré, Jean-Pierre Bouchard, Louise Cossette, Denis Brunet, Michel \\ Vanasse, Bernard Lemieux, Gilles Mathon and Jack Puymirat
}

\begin{abstract}
Background: The aim of the present study was to examine the frequency and the phenotypic manifestations in a FrenchCanadian population with a chromosome 17pl1.2 duplication (Charcot-Marie-Tooth type 1A, CMT-1A). Methods: Molecular analysis were performed by Southern blot using pVAW409R3a probe. Clinical evaluation was carried out according to the scale defined by the European HMSN Consortium. Results: The frequency of duplication was found to be similar in the adult (70.8\%) and pediatric (72.7\%) populations. Onset of symptoms occurred before 20 years of age in $85.7 \%$ of adult cases and before the age of 5 in $80 \%$ of the pediatric cases. The classical CMT syndrome was observed in $77 \%$ of the cases and the syndrome was associated with additional features in $15 \%$ of cases in the adult population. All the children presented with classical CMT syndrome with no additional features. There was a significant correlation between the disability score and the duration of the disease but no correlation was found between median nerve conduction velocity and the functional handicap, the age at onset or the duration of the disease. In one family, there was a very conspicuous anticipation over five observed generations. Conclusion: This study reveals that the age at onset, the clinical and electrophysiological variability as well as the functional disability variations in a French-Canadian population did not differ from those reported in other populations.
\end{abstract}

RÉSUMÉ: Étude clinique et électrophysiologique, dans la population canadienne française, de la maladie de Charcot-Marie-Tooth de type 1A associée à une duplication en 17p11.2. Introduction: Le but de cette étude était d'examiner la fréquence et les manifestations phénotypiques de la maladie de Charcot-Marie-Tooth de type $1 \mathrm{~A}(\mathrm{CMT}-1 \mathrm{~A})$ associée à une duplication en $17 \mathrm{p} 11.2$ dans la population canadienne française. Méthodes: Une analyse moléculaire a été faite par buvardage de Southern au moyen de la sonde pVAW409R3a. Une évaluation clinique a été faite selon l'échelle définie par le Consortium Européen sur la neuropathie sensitivomotrice héréditaire. Résultats: La fréquence de la duplication était la même chez les adultes (70.8\%) et chez les enfants (72.7\%). Le début des symptômes était survenu avant l'âge de 20 ans chez $85.7 \%$ des adultes et avant l'âge de 5 ans chez 80\% des enfants. Le syndrome classique du CMT a été observé dans 77\% des cas et ce syndrome était associé à des manifestations additionnelles chez $15 \%$ des cas adultes. Tous les enfants présentaient le syndrome CMT classique sans manifestations additionnelles. Il existait une corrélation significative entre le score à l'échelle d'invalidité et la durée de la maladie, mais aucune corrélation entre la vitesse de conduction dans le nerf médian et l'invalidité fonctionnelle, l'âge de début ou la durée de la maladie. Dans une famille, nous avons observé une anticipation évidente d'une génération à l'autre sur cinq générations. Conclusion: Cette étude révèle que l'âge de début, la variabilité clinique et électrophysiologique ainsi que les variations de l'invalidité fonctionnelle sont les mêmes dans la population canadienne française que ce qui a été rapporté dans d'autres populations.

Can. J. Neurol. Sci. 1999; 26: 196-200

Hereditary sensory and motor neuropathies are a clinically and genetically heterogeneous group of neuromuscular disorders. The most common types, the hypertrophic type, are denominated type I hereditary motor and sensory neuropathy (HMSN-I) or type 1 Charcot-Marie-Tooth (CMT-I). ${ }^{1,2}$ Inheritance is usually autosomal dominant although sporadic cases have been reported. ${ }^{3}$

HMSN-I is itself genetically heterogeneous, with at least two chromosomal loci involved. ${ }^{4}$ The most common form, type Ia, is due to a dominant allele mapping on chromosome 17 associated with either a $1.5 \mathrm{Mb}$ DNA duplication in $17 \mathrm{pl} 1.2-\mathrm{p} 12$, including the peripheral myelin protein-22 (PMP-22) gene g $^{5.6}$ or a point mutation of the PMP-22 gene..$^{7-9}$ A much rarer form, type $\mathrm{Ib}$, is mapped at $1 \mathrm{q} 22-23$ and is associated with point mutations in the myelin Po gene; $;^{10-12}$ two more families in which the disease was

From the Laboratoire de Recherche en Génétique Humaine, CHU Laval, Québec, Canada (N.P., L.C., J.P.), Département des Sciences Neurologiques, Hôpital EnfantJésus, Québec, Canada (J.-P.B., D.B.), Service de Pédiatrie, Hôpital Marie-Enfant, Montréal, Canada (M.V.), Service de Neurologie Pédiatrique, CHU Sherbrooke,

Canada (B.L.), Service de Rhumatologie, CHU Laval, Québec, Canada (G.M.) RECEIVED DECEM8ER 15, 1998. ACCEPTED IN FINAL FORM APRIL 7, 1999.

Reprint requests to: Dr Jack Puymirat, Laboratoire de Recherche en Génétique Humaine, CHU Laval, 2705 Blvd Laurier, Ste-Foy, Québec, Canada G1V 4G2 
not linked to any of the previous loci have been described, suggesting the existence of a third locus (CMT-1C). ${ }^{13}$

The clinical features of HMSN subtypes are similar and comprise with pes cavus, distal muscle weakness and atrophy, absent or diminished deep tendon reflexes, and mild sensory loss. HMSN-I shows greatly reduced motor nerve conduction velocities (NCV) of less than $38 \mathrm{~m} / \mathrm{sec}$ and, on biopsy, the presence of onion bulbs formed by a process of de- and remyelination. The genetic heterogeneity of the disease raised the possibility of specific clinical features for each HMSN-I subtype. The clinical features of HMSN-I were reported by Harding and Thomas. ${ }^{14}$ This latter study, however, did not distinguish between the HMSN-IA and HMSN-IB subtypes because the genetic defect was not identified at that time. More recently, two studies have examined the clinical, electrophysiological and nerve biopsy findings in large series of cases with $17 \mathrm{p} 11.2$ duplication. ${ }^{15,16}$ These studies revealed that the same genetic defect is associated with variable phenotypic manifestations in the age at onset, clinical and electrophysiological features and clinical severity. This has led to the hypothesis that additional genetic or environmental factors related to peripheral myelin 22 expression could be involved in the expression of the disease. ${ }^{16}$

The aim of the present study was to examine the frequency, age at onset and clinical manifestations in a French-Canadian population with CMT-1A associated with $17 \mathrm{p} 11.2$ duplication. We also wanted to determine whether the phenotypic variabilities observed in the European populations of other studies were also present in the French-Canadian community, which is known to comprise a genetically homogenous population. ${ }^{17}$

\section{Patients and Methods}

The affected subjects were studied either at the adult Neuromuscular Disease Clinic of the "Institut de Réadaptation en déficience physique du Québec" (IRDPQ), or one of the pediatric Neuromuscular Clinics of Montréal and Sherbrooke. All the patients were examined by the authors.

The family pedigrees were reconstructed in order to establish the pattern of inheritance and to allow a discrimination between familial and sporadic cases. A standard clinical and electrophysiological evaluation was carried out in all families. The criteria adopted for including an affected subject as HMSN-I in the study were those defined by the European HMSN Consortium; clinical features of HMSN-I such as slowly progressive symmetrical muscle wasting and weakness, predominantly in the distal part of the lower limbs, severely decreased motor conduction velocity (median nerve conduction velocity $<38 \mathrm{~m} / \mathrm{s}$ ), absence or marked decrease of sensory nerve action potentials in the lower limbs and/or sensory nerve biopsy consistent with a diagnosis of demyelinating neuropathy. The criteria for including affected subjects in the HMSN-II group are: motor conduction velocities that were in the normal range or only mildly decreased, reduced compound muscle action potential amplitudes, small or absent sensory nerve action potentials, and electromyogram evidence of denervation in distal muscles.

\section{Clinical Features}

The age at onset for each patient was determined by asking the patients or the parents about the age at which the first symptoms appeared.
The functional handicap was assessed according to a ninepoint disability scale as described by Birouk et al. ${ }^{16} 0=$ normal; $1=$ normal, but presence of cramps and fatigability; 2 = inability to run; 3 = walking difficult but still possible unaided; $4=$ able to walk with a cane; $5=$ able to walk with crutches; $6=$ able to walk with a walker; $7=$ wheelchair bound; $8=$ bedridden.

\section{Electrodiagnostic Procedures}

All propositi and most of their relatives participating in the study underwent nerve conduction studies (NCS) using a NihonKohden (Neuropack-2XPD) or a TECA TD 20 model. Motor conduction velocities (MCV) were obtained for the median, ulnar and peroneal nerves. Sensory action potentials (SAP) were recorded, following antidromic stimulation of the median and ulnar nerves, by ring electrodes on the first and fourth fingers. The amplitude of the motor and sensory responses were then computed.

\section{Molecular Analysis}

Genomic DNA extracted from venous blood samples was digested with $M s p I$, separated by electrophoresis on $0.9 \%$ agarose gel and transferred to a nylon membrane (Hybond $\mathrm{N}$, Amersham). A single copy fragment of the probe pVAW409R3a (D17S122) was labelled with ${ }^{32} \mathrm{P}-\mathrm{dCTP}$ by a random priming method. This probe detects three $M s p$ I alleles with sizes of 2.8, 2.7 and $1.9 \mathrm{~kb}$; in affected subjects the duplication is shown by the presence of all three $M s p I$ alleles or two $M s p I$ alleles, one of them giving a stronger hybridization signal. Filters were exposed to a phospho Imager (Molecular Dynamics, Sunnyvale, CA) storage screen and signals were then measured in the phospho Imager.

\section{RESULTS}

\section{Molecular Analysis}

Of the 56 families that were studied, 20 came from a pediatric neuromuscular clinic and 36 from an adult neuromuscular clinic. The classification of HMSNs based on clinical and electrophysiological criteria revealed that the percentage of HMSN-I and HMSN-II subtypes are similar in the adult and pediatric populations ( 80.5 and $75 \%$ for HMSN-I; 19.5 and $25 \%$ for HMSN-II) (Table 1).

Forty-four families (29 and 15 from adult and pediatric populations, respectively) with a clinical diagnostic of HMSN-I were tested with the probe pVAW409R3a. Affected subjects from 35 families proved to be heterozygotes and hence informative for the probe. This led to the exclusion of the nine families which included only non-informative (homozygote) subjects for the probe.

A 17p11.2 duplication was observed in 17 and 8 families diagnosed respectively at an adult or pediatric clinic. The estimated duplication frequency was 70.8 and $72.7 \%$ for the adult and pediatric populations (Table 2).

Table 1: Clinical classification of HMSN in Québec.

\begin{tabular}{|c|c|c|}
\hline \multirow[t]{2}{*}{ Population } & HMSN-I & HMSN-II \\
\hline & \multicolumn{2}{|c|}{ Number of families } \\
\hline Adult & $29(80.5 \%)$ & $7(19.5 \%)$ \\
\hline Pediatric & $15(75 \%)$ & $5(25 \%)$ \\
\hline
\end{tabular}

The percentages refer to the total number of families. 
Table 2: Duplication frequency in informative families for the probe pVAW409R3.

\begin{tabular}{lcccc} 
& Tested families & Informative families & Families showing duplication & Duplication frequency, \% \\
\hline Adult population & 29 & 24 & 17 & 70.8 \\
Pediatric population & 15 & 11 & 8 & 72.7 \\
\hline Total & 44 & 35 & 25 & 71.75 \\
\hline
\end{tabular}

Informative families are families in which at least one affected member has been proved to be heterozygote and hence informative for the probe.

\section{Clinical Features}

Of the 44 patients ( 25 were probants and 19 were members of kindreds) from the 25 families showing duplication, 24 were male ( 18 adults and 6 children) and 20 female ( 14 adults and 6 children). Their mean age at the time of examination and DNA testing was $30,4 \pm 19,1$ (mean \pm SD) for the total sample, and $40,8 \pm 14$ and $9,75 \pm 4,3$ for the adult patients and children, respectively. A positive family history consistent with autosomal dominant inheritance was present in 15 families. The remainder were either sporadic (five patients) or of uncertain inheritance (five patients). The mean age at onset of symptoms was $10.3 \pm$ 11.4 years for the total sample, $13.3 \pm 12.4$ years (range 1-52) and $2.66 \pm 2.17$ (range 1-7) for the adult and children, respectively. The age at onset of symptoms was impossible to determine in four patients who where diagnosed at the examination.

The clinical features are summarized in Table 3 . The classical CMT syndrome, namely distal muscle wasting, weakness, sensory loss, areflexia and foot deformities was observed in 34 patients $(77 \%)$. Four patients exhibited only areflexia (9\%), and one patient was clinically asymptomatic (3\%). In the adult cases, the classical CMT syndrome was observed in 24 subjects $(75 \%)$. Two patients exhibiting only areflexia (6\%) and one subject was clinically asymptomatic (3\%). Enlarged nerves were observed in $35 \%$ of families. The CMT syndrome was associated with other features in 5 patients: in two of them it was associated with a hand postural tremor $(6 \%)$ and in two others, with hypoacousia (6\%), and in another with a congenital dislocation of the hips. None of the patients had pyramidal or cerebellar signs. In the children cases, the classical CMT syndrome was observed in 10 subjects $(83 \%)$ with only two of them only exhibiting areflexia $(17 \%)$. None of the children were clinically asymptomatic and none of them showed any association with other manifestations. A delay in motor development was noted in $50 \%$ of the cases.

Functional disability was mild or absent (scale 0,1 ) in 23 patients $(52 \%) ; 13$ patients $(29.5 \%)$ were at stage 2 or 3 ; and 7 patients $(15,9 \%)$ were at stage 3 or greater. Only one patient (2.2\%) was wheelchair bound. There was a significant correlation between the disability score and the duration of the disease

Table 3: Summary of clinical features.

\begin{tabular}{ll}
\hline Phenotype & Number of patients (\%) \\
\hline Classical CMT syndrome & $34(77 \%)$ \\
Areflexia only & $4(9 \%)$ \\
Asymptomatic & $1(3 \%)$ \\
& \\
CMT associated with additional features & \\
$\quad$ Postural hand tremor & 2 \\
$\quad$ Hypoacousia & 1 \\
$\quad$ Congenital dislocation of the hips & 44 \\
\hline Total &
\end{tabular}

(Figure 1). There was, however, a great variability in the functional disability even within the same family.

\section{Clinical Neurophysiology}

Motor nerve conduction velocity (NCV) was measured for the median nerve (MNCV) by recording the abductor pollicis brevis. The mean values were $19 \pm 6.5$ and $22.6 \pm 9.8 \mathrm{~m} / \mathrm{s}$ for the adult patients and children respectively, and $20.91 \pm 7.5 \mathrm{~m} / \mathrm{s}$ (mean \pm SD) with a range of $10-37 \mathrm{~m} / \mathrm{s}$ for the total sample. The mean value for the ulnar nerve was $19.4 \pm 6.8$ (range of $6-36 \mathrm{~m} / \mathrm{s}$ ). A value for the lower limbs was less frequently obtained. The mean value for the peroneal nerve was $18.5 \pm 6.5$ (range of $13-34 \mathrm{~m} / \mathrm{s}$ ), respectively. There was a large variability in NCV not only between different families but also within the same family. Slowing of NCV was associated with an increase in distal motor latency (DML) and a decrease in compound muscle action potential (CMAP) (Table 4). Sensory nerve action potentials were usually absent or of severely depressed amplitude. The presence of duplication was always associated with NCV slowing. There was no correlation between MNCV and the age at onset (Figure 2A) or the duration of the disease (Figure $2 \mathrm{~B}$ ). Although the functional disability seems to correlate with the decrease in motor nerve conduction velocity, this was not significant $(r=0.15)$.

\section{A Selected Case}

This 10-year-old child began to walk at the age of 19 months. Neurological examination at the age of 5 years showed muscle weakness in the lower limbs and areflexia. When reviewed at the age of 10 years she showed muscle weakness and wasting in the upper and lower limbs and areflexia. All sensory modalities were retained. Peripheral nerve thickening was evident.

In her family, the father, grandfather, great grandfather and her great, great grandfather were affected. Her father had a normal motor development. Neurological examination at the age of seven years showed no definite muscle wasting or weakness. His tendon reflexes were all absent. There was unilateral pes cavus. Subsequently, progressive limb weakness developed. When reviewed at the age of 30 years, he showed a generalized wasting and weakness in the four limbs which was total distally. All sensory modalities were impaired in the upper and lower limbs. He had bilateral pes cavus. His peripheral nerves were thickened. His scale of disability was about 3 .

Table 4: Electrophysiological study in HMSN-IA.

\begin{tabular}{lccc}
\hline & Median nerve & Ulnar nerve & Peroneal nerve \\
\hline MNCV (m/s) & $20.91 \pm 7.5$ & $19.4 \pm 6.8$ & $18.45 \pm 6.54$ \\
DML (ms) & $11.8 \pm 4.2$ & $8.65 \pm 3.5$ & $9.43 \pm 2.87$ \\
CMAP $(\mathrm{mV})$ & $2.26 \pm 2.5$ & $2.74 \pm 2.22$ & $1.43 \pm 1.04$ \\
\hline
\end{tabular}

$\mathrm{MNCV}=$ motor nerve conduction velocity; $\mathrm{DML}=$ distal motor latency; CMAP = compound muscle action potential. Results are the mean \pm S.D. 


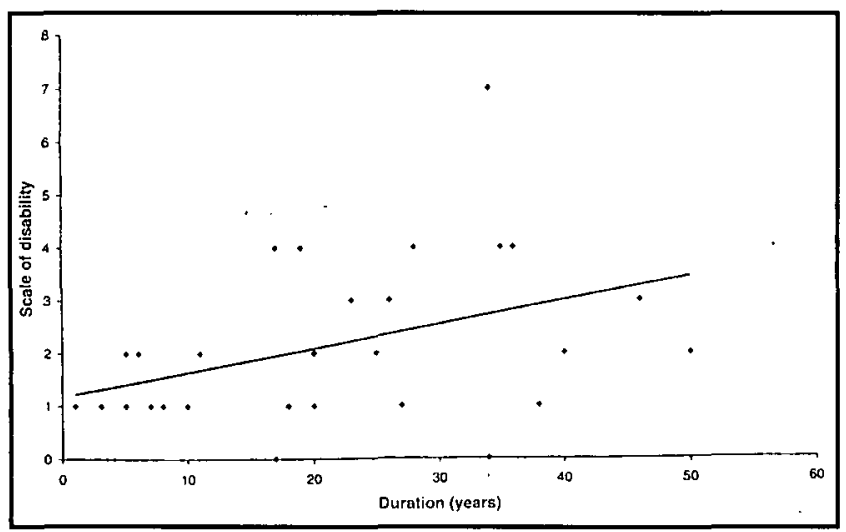

Figure 1: Significant correlation between the functional handicap and the duration of the disease. The functional handicap was assessed according to a nine-point disability scale as described in "Patients and Methods". The age at onset of symptoms was impossible to determine in five patients and these patients were therefore excluded. Twelve patients had a same age at onset of symptoms and a same functional handicap as others, and they appear as a single point in the curve. $\quad(r=0.42$, $p<0.018$ ).

The first neurological examination of the grandfather performed at the age of 30 years showed moderate wasting and weakness in all the four limbs. At that time he had no functional handicap. His condition had continued to deteriorate. When reviewed at the age of 64 years, his disability score was about 4 . The great grandfather was similarly but less severely affected than the grandfather. The disease seems to have begun more tardily and neurological examination at the age of 41 years showed no muscle weakness but only peripheral nerve thickening. The great, great grandfather had bilateral pes cavus but no muscle weakness or wasting.

Molecular analysis revealed the presence of the same $1.5 \mathrm{Mb}$ duplication in the patient, her father and grandfather.

\section{Discussion}

The frequency of HMSN-I and HMSN-II is similar in the adult and pediatric French Canadian populations and is in good agreement with the frequency of both subtypes reported in the United States. ${ }^{18,19}$ The frequency of HMSN-IA $(71 \%)$ is also similar in the adult and pediatric population and agrees with the frequency of HMSN-IA reported in European (70.7\%), ${ }^{20}$ American (68\%) ${ }^{19}$ and Southern Welsh (60 to $\left.80 \%\right)^{21}$ populations. This indicates that the frequency of HMSN-IA in the French Canadian population does not differ from the frequency of HMSN-IA elsewhere in the world. It is of note that our study might suffer from a selection bias, given that the probants were referred from neuromuscular clinics. We can suspect that mildly affected families were underestimated and that HMSN-I were overestimated relative to HMSN-II, as the former can be readily suspected from nerve conduction data in an individual patient.

In adult patients with HMSN-IA, onset was acknowledged in the first decade in $64.8 \%$ of cases and before the age of 15 in $82 \%$ of patients. This is in agreement with a recent study showing that onset of HMSN-IA occur in the first two decades in $85 \%$ of cases. ${ }^{15}$ Our results, however, differ from those reported by Birouk et al. ${ }^{16}$ They reported that in only $50 \%$ of cases did the onset of the disease occur in the first decade and only in $70 \%$

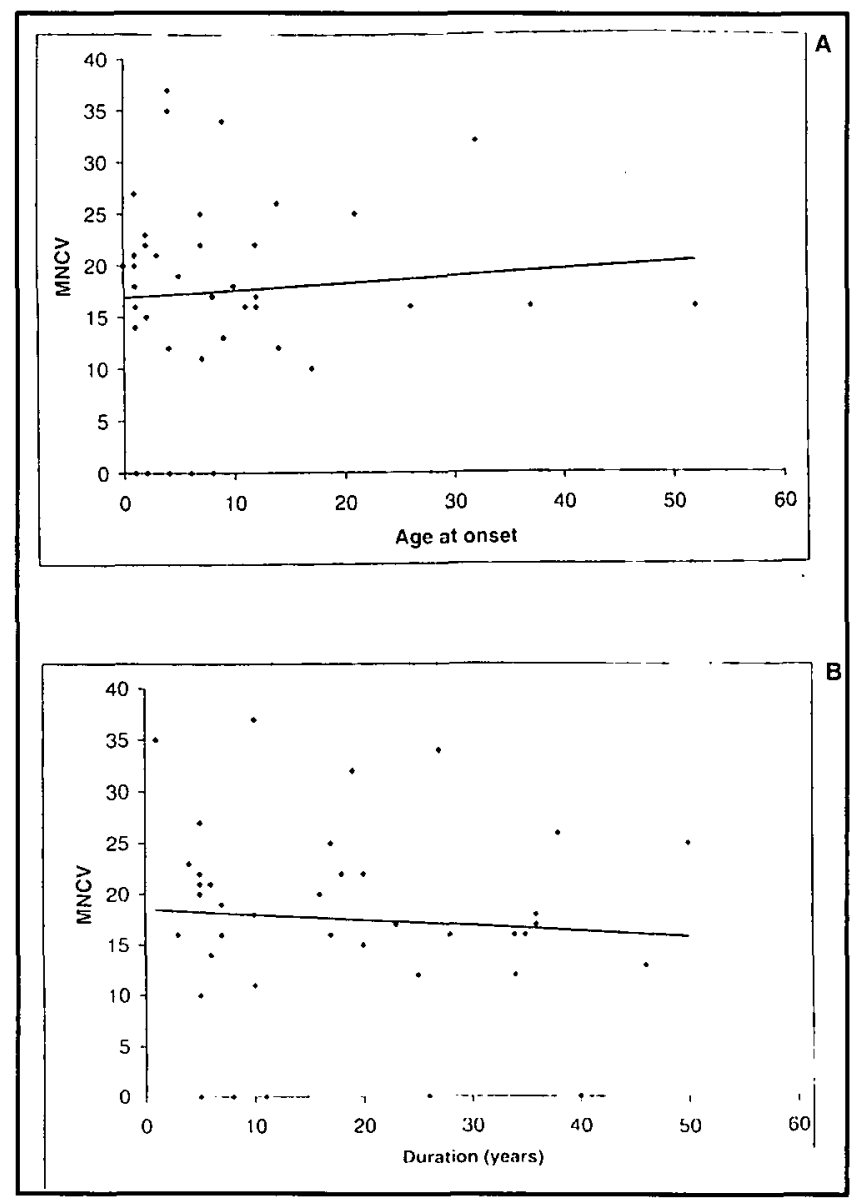

Figure 2: Regression analysis between median nerve conduction velocity (MNCV) and age at onset (A) and duration of the disease (B). There was no significant correlation between NMCV and age at onset $(r=$ $0.109, p=0.59)$ or duration of the disease $(r=0.166, p=0.41)$.

before the age of 20 . Because the age at onset was determined by questioning the patients about their first disabling symptoms, the determination of age at onset could be imprecise, especially in older patients who may not remember precisely the age at which the first symptoms occurred. To define more precisely the age at onset of symptoms in HMSN-IA, we examined the age at onset of HMSN-IA in patients diagnosed in pediatric clinics. No CMT diagnosis was done in children aged between the age of 10 and 18 years whereas, by questioning adult subjects, the first symptoms had occurred between 10 and 18 years in $32 \%$ of them. Onset occurred in all cases before the age of 10 and, in $80 \%$ of the cases before the age of 5. This suggests that the onset of HMSN-IA occurs before 5 years of age in a high percentage of cases.

Most patients have the classical HMSN symptoms with areflexia, foot deformities, and distal muscle weakness and wasting, predominately in the lower limbs. In 6 of the patients, a HMSNIA syndrome was accompanied by other features. In two of the patients, the HMSN was associated with an upper limb postural tremor that could be categorized as the Roussy-Lévy syndrome. In two other patients, the HMSN was associated with an hypoacousia. One patient had a congenital dislocation of the hips. The variability of the clinical features in the FrenchCanadian population did not differ from that described in other populations. $^{16}$ 
Functional disability was judged on a scale based on the ability to walk and run as described by Birouk et al. ${ }^{16}$ Most patients $(80 \%)$ had a low to moderate functional scale disability score. Only $19 \%$ of them had a score above 3 and only one of them was wheelchair bound. These results confirm those reported by Birouk et al. ${ }^{16}$ indicating that severe disability is rare in this disease.

In a family followed during 5 generations, we noted that symptoms appeared at an earlier age and were more severe in successive generations. This suggests the possibility of an anticipation phenomenon in this family. To our knowledge, this is the first report showing the possibility of anticipation in CMT1A associated with duplication. A progressive increase in severity and an earlier onset from the first to the third generation was recently reported in a family with CMT1A associated with a point mutation in the PMP22 gene. ${ }^{22}$ It is of note that in one (case 30) of selected cases reported by Thomas et al. ${ }^{15}$ it was also noted that the father and the paternal grandfather of a patient with CMT IA were less severely affected. The authors did not, however, emphasize the possibility of an anticipation phenomenon. Because of the stability of the $1.5 \mathrm{Mb}$ duplication over three generations in this family, it is likely that other factors play a role in the phenotypic expression of the disease.

The severely reduced conduction velocity in peripheral nerves constitutes a reliable marker for screening affected at-risk individuals. In the families in our study, we never observed a normal conduction velocity associated with a duplication, indicating that free-carrier status does not exist or is very rare. The highest value found here for the median nerve conduction velocity was $37 \mathrm{~m} / \mathrm{s}$ which is in good agreement with other studies. ${ }^{15,16}$ The absence of any correlation between MNCV and clinical severity found in the present study agrees with previous reports ${ }^{3,14.23}$ whereas others have reported that median MNCV was inversely related to functional disability. ${ }^{16,24}$ These differences could be attributed to the lower number of patients in the present study for whom the onset of the disease occurred after 30 years of age and in whom the disease had been present for more than 40 years.

In conclusion, the frequency, the age at onset, and the variability in clinical features did not differ for this French-Canadian population from that reported for other populations.

\section{ACKNOWLEDGEMENTS}

We are grateful for all the interest and help from the participating CMT families. The authors acknowledge the expert help of Dr E. Le Guern, Unité INSERM U289, Paris, for molecular analysis. The contribution provided by Mrs. Lise Dumas from the "Institut de Réadaptation en Déficience Physique du Québec" (IRDPQ) is also gratefully acknowledged. This study was supported by the "Consortium en Réadaptation de l'Est du Québec".

\section{REFERENCES}

1. Thomas PK, Calne DB, Stewart T. Hereditary motor and sensory polyneuropathy (peroneal muscular atrophy). Ann Hum Genet 1974; 38: 111-153.

2. Dyck PJ. Definition and basis of classification of hereditary neuropathy with neuronal atrophy and degeneration. $I n$ : Dyck PJ, 3. Thomas PK, Lambert EH, editors. Peripheral Neuropathy. Philadelphia: W.B. Saunders, 1975: 755-758.
3. Dyck PJ, Lambert EH. Lower motor and primary sensory neuron diseases with peroneal muscular atrophy. I. Neurologic, genetic, and electrophysiologic findings in hereditary polyneuropathies. Arch Neurol 1968; 18: 603-618.

4. Harding AE. From the syndrome of Charcot, Marie and Tooth to disorders of peripheral myelin proteins. Brain 1995; 118: 809818.

5. Raeymaekers P, Timmerman V, Nelis E, et al. Duplication in chromosome $17 \mathrm{p} 11.2$ in Charcot-Marie-Tooth neuropathy type la (CMT 1a). Neuromuscul Disord 1991; 1: 93-97.

6. Hallam PJ, Harding AE, Berciano J, Barker DF, Malcom S. Duplication of part of chromosome 17 is commonly associated with hereditary motor and sensory neuropathy type I (CharcotMarie-Tooth disease type 1) Ann Neurol 1992; 31: 570-6002.

7. Valentijn LJ, Baas F, Wolterman RA, et al. Identical point mutations of PMP22 in Trembler-J mouse and Charcot-Marie-Tooth disease type 1a. Nature Genet 1992; 2: 288-291.

8. Roa BB, Garcia CA, Suter U, et al. Charcot-Marie-Tooth disease type 1A. Association with a spontaneous point mutation in the PMP22 gene. N Engl J Med. 1993; 329: 96-101.

9. Nelis E, Timmerman V, De Jonghe P, Van Broeckhoven C. Identification of a 5' splice site mutation in the PMP-22 gene in autosomal dominant Charcot-Marie-Tooth disease type 1. Hum Mol Genet 1994; 3: 515-516.

10. Bird TD, Ott J, Giblett ER. Evidence for linkage of Charcot-MarieTooth neuropathy to the Duffy locus on chromosome 1. Am J Hum Genet 1982; 34: 388-394.

11. Su Y, Brooks DG, Li L, et al. Myelin protein zero gene mutated in Charcot-Marie-Tooth type 1B patients. Proc Natl Acad Sci USA 1993; 90: 10856-10860.

12. Latour $P$, Blanquet $F$, Nelis $E$, et al. Mutations in the myelin protein zero gene associated with Charcot-Marie-Tooth disease type 1B. Hum Mutat 1995; 6: 50-54.

13. Chance PF, Bird TD, O'Connell P, et al. Genetic linkage and heterogeneity in type I Charcot-Marie-Tooth disease (hereditary motor and sensory neuropathy type I). Am J Hum Genet 1990; 47: 915-925.

14. Harding AE, Thomas PK. The clinical features of hereditary motor and sensory neuropathy types I and II. Brain 1980; 103: 259-280.

15. Thomas PK, Marques W Jr, Davis MB, et al. The phenotypic manifestations of chromosome 17p11.2 duplication. Brain 1997; 120: 465-478.

16. Birouk N, Gouider R, Le Guern E, et al. Charcot-Marie-Tooth disease type 1A with 17p11.2 duplication. Clinical and electrophysiological phenotype study and factors influencing disease severity in 119 cases. Brain 1997; 120: 813-823.

17. Bouchard G, de Braekeleer M. Mouvements migratoires, effets fondateurs et homogénéisation génétique. $I n$ : Bouchard $\mathrm{G}$ and $\mathrm{De}$ Braekeleer M, eds. Histoire d'un Génome. Presses de l'Université du Québec, 1991; 281-321.

18. Ionasescu VV, Ionasescu R, Searby C. Screening of dominantly inherited Charcot-Marie-Tooth neuropathies. Muscle \& Nerve 1993; 16: 1232-1238.

19. Ionasescu VV. Charcot-Marie-Tooth neuropathies: from clinical description to molecular genetics. Muscle \& Nerve 1995; 18: 267-275.

20. Nelis E, Van Broeckhoven C, De Jonghe P, et al. Estimation of the mutation frequencies in Charcot-Marie-Tooth disease type 1 and hereditary neuropathy with liability to pressure palsies: a European collaborative study. Eur J Hum Genet 1996; 4: 25-33.

21. Wise CA, Garcia CA, Davis SN, et al. Molecular analyses of unrelated Charcot-Marie-Tooth (CMT) disease patients suggest a high frequency of the CMTIA duplication [see comments]. Am J Hum Genet 1993; 53: 853-863.

22. Marrosu MG, Vaccargiu S, Marrosu G, et al. A novel point mutation in the peripheral myelin protein 22 (PMP22) gene associated with Charcot-Marie-Tooth disease type 1A. Neurology 1997; 48: 489-493.

23. Bouche $\mathrm{P}$, Gherardi R, Cathala HP, Lhermitte F, Castaigne P. Peroneal muscular dystrophy. Part I. Clinical and electrophysiological study. J Neurol Sci 1983; 61: 389-399.

24. Hoogendijk JE, De Visser M, Bolhuis PA, et al. Hereditary motor and sensory neuropathy type I: clinical and neurographical features of the 17p duplication subtype. Muscle \& Nerve 1994; 17: 85-90. 